\title{
The Effect of Tin on PECVD-Deposited Germanium Sulfide Thin Films for Resistive RAM Devices
}

\author{
Rene Rodriguez*, Benjamin Poulter, Mateo Gonzalez, Fadil Ali, Lisa D. Lau, McKenzie Mangun \\ Department of Chemistry, Idaho State University, Pocatello, ID, USA \\ Email: ^rodrrene@isu.edu, poulbenj@isu.edu, gonzmate@isu.edu, faa.20129@gmail.com, laulisa@isu.edu, mangmck2@isu.edu
}

How to cite this paper: Rodriguez, R., Poulter, B., Gonzalez, M., Ali, F., Lau, L.D. and Mangun, M. (2017) The Effect of Tin on PECVD-Deposited Germanium Sulfide Thin Films for Resistive RAM Devices. Materials Sciences and Applications, 8, 188196.

https://doi.org/10.4236/msa.2017.82012

Received: December 31, 2016

Accepted: February 4, 2017

Published: February 7, 2017

Copyright ( 92017 by authors and Scientific Research Publishing Inc. This work is licensed under the Creative Commons Attribution International License (CC BY 4.0).

http://creativecommons.org/licenses/by/4.0/ (c) (i) Open Access

\begin{abstract}
Resistive RAM is a promising, relatively new type of memory with fast switching characteristics. Metal chalcogenide films have been used as the amorphous semiconductor layer in these types of devices. The amount of crystallinity present in the films may be important for both reliable operation and increased longevity of the devices. Germanium sulfide films can be used for these devices, and a possible way to tune the crystalline content of the films is by substituting $\mathrm{Sn}$ for some of the Ge atoms in the film. Thin films of $\mathrm{Ge}_{\mathrm{x}} \mathrm{Sn}_{\mathrm{y}} \mathrm{S}_{\mathrm{z}}$ containing varying amounts of tin were deposited in a plasma enhanced chemical vapor deposition reactor. Films with $2 \%, 8 \%, 15 \%, 26 \%$, and $34 \%$ atomic percentage Sn were deposited to determine crystallinity and structural information with XRD and Raman spectroscopy. Based on these depositions it was determined that at about $8 \%$ Sn content and below, the films were largely amorphous, and at about $26 \%$ Sn and above, they appeared to be largely crystalline. At $15 \%$ Sn composition, which is between $8 \%$ and $26 \%$, the film is more a mixture of the two phases. Based on this information, current-voltage (IV) curves of simple memory switching devices were constructed at $5 \%$ Sn (in the amorphous region), at $25 \%$ Sn (in the crystalline region), and at $15 \%$ (in the mixed region). Based on the IV curves from these devices, the $15 \%$ composition gave the best overall switching behavior suggesting that a certain degree of order in the semiconductor layer is important for RRAM devices.
\end{abstract}

\section{Keywords}

Germanium-Tin Sulfide Thin Films, PECVD, Resistive RAM

\section{Introduction}

Germanium chalcogenides have been successfully employed in the production of 
phase memory and in resistive RAM, (conductive bridging RAM) [1] [2] [3]. Chalcogenide glasses are an essential layer in both of these types of memory devices. Early studies have shown that the incorporation of Sn or Sb into the germanium chalcogenide layer increases their stability of these semiconductor layers for use in these devices [4] [5]. Previous studies by our group have shown that PECVD is an efficient method for depositing both germanium sulfide and germanium selenide thin films with good thickness and quality control [6] [7], and slight modification of this methodology would likely provide an efficient method for production of germanium chalcogenide films with controlled percentages of $\mathrm{Sn}$ incorporation. The ability to control the percentage of Sn deposited into the germanium chalcogenide thin film layer provides an opportunity to study tin's effect on the material properties of the germanium chalcogenide thin films, and allows for a deeper understanding of how Sn incorporation may lead to improved phase memory and resistive-RAM (RRAM) memory.

Tin sulfide exists as several different stoichiometric phases including SnS, $\mathrm{SnS}_{2}$, and $\mathrm{Sn}_{2} \mathrm{~S}_{3}$ and deposition of the different phases has been reported [8]. Notably, deposition of pure $\mathrm{SnS}_{2}$ most often results in a crystalline material [8]. The incorporation of $\mathrm{Sn}$ into the $\mathrm{GeS}_{2}$ layers is likely to be affected by several factors including similarities or differences in crystalline shape, bond enthalpies, and atomic radius. Elemental $\mathrm{Sn}$ has an atomic radius of $141 \mathrm{pm}$ whereas $\mathrm{Ge}$ has an atomic radius of $123 \mathrm{pm}$. The $4+$ ions of each have diameters of 45 and $53 \mathrm{pm}$ respectively.

In this study $\mathrm{SnCl}_{4}$ was added to the PECVD of $\mathrm{GeS}_{2}$ films, at various concentrations, to study the effect of $S n$ addition on the structure of the thin films and their behavior in RRAM memory devices. $\mathrm{SnCl}_{4}$ was added to produce $\mathrm{Ge}_{\mathrm{x}} \mathrm{Sn}_{\mathrm{y}} \mathrm{S}_{\mathrm{z}}$ films containing $2 \%, 8 \%, 15 \%, 26 \%$, and $34 \%$ Sn based on atomic percentage. Raman spectroscopy and X-ray diffraction were used to probe structural changes and similarities in the deposited films. Based on the information from these depositions simple RRAM devices were constructed at low Sn content (5\%), middle Sn content (15\%), and relatively high Sn content (25\%), and the currentvoltage curves were measured and compared for the devices made with Sn content at these low, middle, and high atomic content ranges.

\section{Materials and Methods}

\subsection{Chamber and Gases}

The PECVD parallel plate reactor used in this experiment was a prototype reactor used in prior investigations. The reactor has been previous described in detail [9]. The gases and reactants used in the reactor during the experiment were ultrapure argon (99.999\% Scott Specialty Gases), pure $\mathrm{H}_{2} \mathrm{~S}$ (99.5\% Matheson Tri-Gas), $\mathrm{GeCl}_{4}$ and $\mathrm{SnCl}_{4}$ (99.99\% and $98 \%$ respectively, Strem Chemicals).

The gas phase resulting from the vapor pressures of the $\mathrm{GeCl}_{4}$ and $\mathrm{SnCl}_{4}$ liquids provided the Ge and $\mathrm{Sn}$ components for the $\mathrm{Ge}_{\mathrm{x}} \mathrm{Sn}_{\mathrm{y}} \mathrm{S}_{\mathrm{z}}$ thin films. The vapor pressure of the $\mathrm{GeCl}_{4}$ at $22^{\circ} \mathrm{C}$ was sufficient enough to drive the mass flow con- 
troller allowing the set flow of $\mathrm{GeCl}_{4}$ to reach the reactor without heating. The vapor pressure of the $\mathrm{SnCl}_{4}$ was less under the same temperature conditions, and its flow required the application of heat tape to the reagent canister and gas line. The canister was kept at $40^{\circ} \mathrm{C}$ and the line $45^{\circ} \mathrm{C}$ by means of two separate power sources. Also for some of the depositions, ultrapure argon was bubbled through the $\mathrm{SnCl}_{4}$, to provide sufficient backing pressure for control by the mass flow controller.

For all experiments, the pressure inside the chamber was maintained between 194.7 and 197.3 $\mathrm{Pa}$ by means of an automatic control valve supplying argon to the pump to control the pumping speed. The gases were fed through the top platen and showerhead in a continuous flow. The power of the plasma was kept at a constant $22 \mathrm{~W}$ for all depositions. The temperature of the substrate ranged from $140^{\circ} \mathrm{C}-150^{\circ} \mathrm{C}$.

\subsection{Substrates}

Doubly polished pure crystalline silicon wafers in the 111 orientation, and glass microscope slides were used as the target substrates. The silicon wafer was broken up into equally sized pieces and then they, along with the glass microscope slides were placed on an unbroken silicon wafer and consistently oriented in the chamber on the grounded electrode. Thicknesses of the resultant films were determined by an Ambios Technologies XP-100 profilometer.

\subsection{Film Deposition Parameters}

The flow rates of the $\mathrm{GeCl}_{4}$ and $\mathrm{H}_{2} \mathrm{~S}$ reactants were kept constant for each deposition. $\mathrm{H}_{2} \mathrm{~S}$ was kept at $12.0 \mathrm{sccm}$ and the $\mathrm{GeCl}_{4}$ at $1.0 \mathrm{sccm}$. The argon flow rates varied, depending on the deposition, in order to keep the total gas pressure in the reactor constant between depositions. The $\mathrm{SnCl}_{4}$ flow rate was the main variable throughout the course of the entire experiment. As indicated previously, some of the depositions used argon backing on the $\mathrm{SnCl}_{4}$ line and the flow rates were corrected for this mixture. The flows of the depositions under these parameters ranged from $3 \mathrm{sccm}$ to $20 \mathrm{sccm}$. There were also a few depositions which used only $\mathrm{SnCl}_{4}$ without any argon backing and the flow rates were calculated based only on the $\mathrm{SnCl}_{4}$ physical properties. The flows of the depositions under these parameters ranged from $5 \mathrm{sccm}$ to $15 \mathrm{sccm}$.

\subsection{Film Analysis}

Film composition and properties were determined using a variety of methods. The chemical make-ups of the films, in atomic percentages, were determined using an Oxford Model 7353 EDS coupled with a LEO Model 1430 SEM. Raman spectroscopy was used to determine the molecular composition of the films. Raman spectra were collected with a Jobin-Yvon Horiba HR-800 Raman microscope using the $647.1 \mathrm{~nm}$ line of a Lexel Model 95L-K2 Kr-ion laser for excitation. These two techniques were combined in order to confirm the identities of the species present in the films. A Bruker D8 Discover XRD, Cu- $\mathrm{K} \alpha$ radiation, 
was used to determine crystallinity of the films.

\subsection{Device Construction}

RRAM devices were constructed by depositing three layers of material, in succession, on a standard microscope slide cut in half lengthwise. The three layers were: a lower aluminum electrode layer, a thin film semiconductor layer, and a silver electrode layer on the top. The construction was performed by first depositing two aluminum lines, roughly $6 \mathrm{~mm}$ wide and separated by $\sim 5 \mathrm{~mm}$ along the length of a microscope slide using a Denton Deskpro magnetron sputter system. The slides were masked with aluminum foil to create the two-line pattern on the slide. The thickness of the deposited lines was roughly 0.5 micrometers. Next, the slides with the aluminum lines were masked with aluminum foil so that $\sim 6 \mathrm{~mm}$ on opposing ends of each line was covered by the foil. This was done to provide a conductive contact point for future testing of the devices. Next the masked slides were placed into the PECVD chamber and the $\mathrm{Ge}_{\mathrm{x}} \mathrm{Sn}_{\mathrm{y}} \mathrm{S}_{\mathrm{z}}$ semiconductor layer was deposited on the exposed parts of the glass slides including the parts of the aluminum lines that were exposed. The thickness of the chalcogenide semiconductor layer was typically $100-200 \mathrm{~nm}$. The final layer of the devices consisted of two $5 \mathrm{~mm}$ wide, $0.4 \mu \mathrm{m}$ thick, silver lines deposited on top of the $\mathrm{Ge}_{\mathrm{x}} \mathrm{Sn}_{\mathrm{y}} \mathrm{S}_{\mathrm{z}}$ semiconductor layer, perpendicular to the aluminum lines. These provided the upper contacts for the RRAM devices, and the silver for the formation of the conductive bridging in the RRAM. When all three layers were present, in the structure described, a total of four devices are created at the intersections of the silver and aluminum lines with the $\mathrm{Ge}_{x} \mathrm{Sn}_{\mathrm{y}} \mathrm{S}_{\mathrm{z}}$ layer sandwiched between the aluminum and silver line intersection.

\subsection{Device Testing}

The RRAM memory devices, constructed with the chalcogenide semiconductor layer, with different percentages of $\mathrm{Sn}$, were tested by constructing current vs voltage curves for each. An ideal RRAM memory device would, at a certain voltage, change nearly instantaneously from a low conductance to much higher conductance condition. This occurs when the Ag upper layer is sufficiently positively charged relative to the $\mathrm{Al}$ bottom layer, that $\mathrm{Ag}$ ions move through the semiconductor layer and form conductive bridges between the $\mathrm{Al}$ and $\mathrm{Ag}$ layers. If the conductance changes by two to three orders of magnitude, this is sufficient for both "off" and "on" memory states. To determine if this behavior is present for the devices constructed with different Sn percentages, current vs voltage curves were gathered. A Keithley Model 2602 SourceMeter was connected to the Ag and $\mathrm{Al}$ electrodes using small flat alligator clips. A graphical program was written in LabVIEW to control the voltage sweeps and simultaneously collect the current measurements. The voltage limits were determined based on the amount of current change seen in the initial sweeps. In some cases higher voltage level sweeps $\pm 3 \mathrm{~V}$ were required to observe significant changes in the current. In other cases significant changes in the current were observable with a sweep of only $\pm 1 \mathrm{~V}$. 


\section{Results and Discussion}

\subsection{EDS Results}

The compositions of the thin films of $\mathrm{Ge}_{\mathrm{x}} \mathrm{Sn}_{\mathrm{y}} \mathrm{S}_{\mathrm{z}}$ deposited with PECVD were found to be close to the desired values of $2 \%, 8 \%, 15 \%, 26 \%$, and $34 \%$ Sn. As mentioned previously, these thin films are the semiconductor film that separates the $\mathrm{Al}$ and $\mathrm{Sn}$ electrodes in the RRAM devices. Based on EDS measurements the atomic ratio of $(\mathrm{Ge}+\mathrm{Sn}) / \mathrm{S}$ varied between 0.6 and 0.9 (average 0.69 ) and in some cases residual $\mathrm{Cl}$ was also measured.

\subsection{XRD Results}

The XRD spectra of these films are shown in Figure 1. The thickness of each of these films was roughly on the order of $1-2$ microns. For the case with $2 \%$ tin, the film is found to be amorphous as there are no sharp peaks presented in the spectrum, but as the atomic concentration of $\mathrm{Sn}$ in the thin films increases, peaks assignable to either $\mathrm{GeS}_{2}$ or $\mathrm{SnS}_{2}$ begin to appear in the spectrum [8] [10] [11]. As the percentage of $\mathrm{Sn}$ increases the peaks generally become sharper and narrower, and reflect the published values for crystalline $\mathrm{SnS}_{2}$. The JCPDS stick spectrum for $\mathrm{SnS}_{2}$ is given in Figure 1 as well for comparison. Crystalline $\mathrm{GeS}_{2}$ also has significant peak at a $2 \theta$ of 15 degrees and so some of the intensity in that XRD peak for high Sn content could be due to $\mathrm{GeS}_{2}$.

\subsection{Raman Results}

The Raman spectra of these films are presented in Figure 2. Note that the prominent peak in the Raman spectrum of nearly pure $\mathrm{GeS}_{2}$ appears at about $342 \mathrm{~cm}^{-1}$, and is associated with the stretch for the tetrahedral $\mathrm{GeS}_{4}$ structure [12] [13]. When $\mathrm{Sn}$ is added to the deposition, a new peak appears at about 312

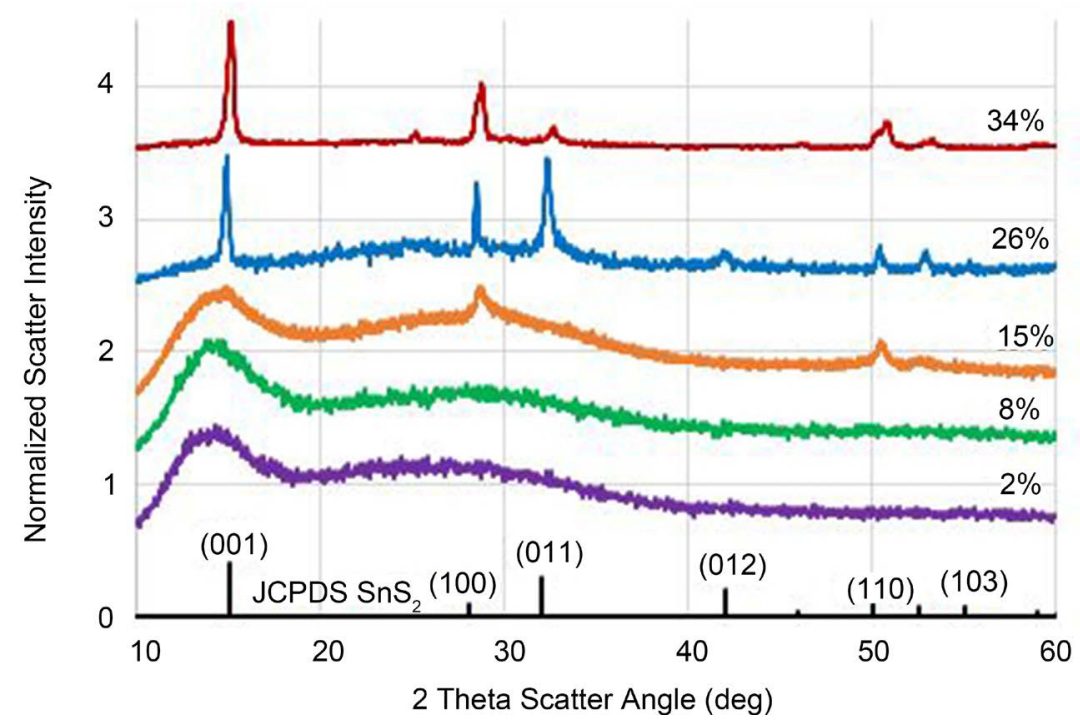

Figure 1. XRD spectra of thin films of 1 - 2 micron thick $\mathrm{Ge}_{\mathrm{x}} \mathrm{Sn}_{\mathrm{y}} \mathrm{S}_{\mathrm{z}}$ thin films where the percentage of Sn present is indicated on the right of each spectrum. The standard XRD spectrum for $\mathrm{SnS}_{2}$, JCPDS: 83-1705, is given on the baseline as a stick spectrum. 


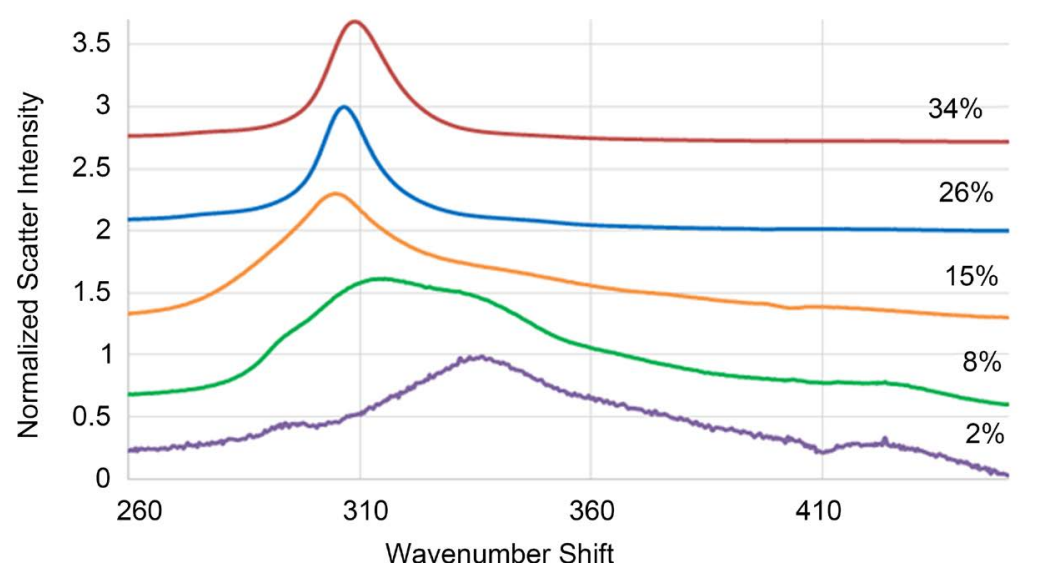

Figure 2. Raman Spectra of thin films of 1 - 2 micron thick $\mathrm{Ge}_{\mathrm{x}} \mathrm{Sn}_{\mathrm{y}} \mathrm{S}_{\mathrm{z}}$ thin films where the percentage of $\mathrm{Sn}$ present is indicated above each spectrum.

$\mathrm{cm}^{-1}$. As the amount of $\mathrm{Sn}$ increases to $8 \%$, a broad peak at around $312 \mathrm{~cm}^{-1}$ becomes more prominent in the spectrum, and the peak at $342 \mathrm{~cm}^{-1}$ broadens and becomes less intense. As the Sn composition increases to $15 \%$, the maximum is now slightly less than $310 \mathrm{~cm}^{-1}$, but the spectrum is still fairly broad. At both $26 \%$ and $34 \% \mathrm{Sn}$, the spectrum has narrowed more significantly with just one prominent peak likely assignable to primarily $\mathrm{Sn}_{2} \mathrm{~S}_{3}$ with some $\mathrm{SnS}_{2}$ at about 307 $\mathrm{cm}^{-1}$ [8] [14]. The broadening and subsequent narrowing of the peaks indicate that the film becomes less ordered at low concentrations of Sn such as at atomic percentages of $2 \%$ and $8 \%$, but at higher concentration of $26 \%$ and $34 \%$, the films have increasing long range order. The $15 \%$ Sn thin film represents that case where some ordering has occurred due to the presence of the tin sulfides, but there is still significant disorder present due to the germanium.

\subsection{Device Testing}

As described previously in the methods section, simple Resistive RAM devices were constructed with an aluminum lower electrode, a silver upper electrode, and the $\mathrm{Ge}_{\mathrm{x}} \mathrm{Sn}_{\mathrm{y}} \mathrm{S}_{\mathrm{z}}$ semiconductor thin film layer sandwiched between the lower and upper conductive layers. The conductivity of each of the devices was measured as a function of the voltage difference between the upper Ag electrode and the lower Al electrode. The voltage was first increased so that the potential of the $\mathrm{Ag}$ was positive relative to the $\mathrm{Al}$ electrode, and then the relative voltage on the Ag electrode was lowered so it was eventually negative relative to the $\mathrm{Al}$ electrode. For the first few cycles, the voltage limits were often set between $+3.0 \mathrm{~V}$ and -3.0 volts. Presumably, this is necessary for pathways and silver ions to form and move through the semiconductor layer. After a few cycles, typically 4 or 5 , the voltage limits are reduced to a narrower range. These current-voltage curves (I-V curves) were collected over several cycles to determine the repeatability and durability of the RRAM device. The I-V curves generated from devices containing 5\% Sn, 15\% Sn, and 25\% Sn are presented in Figure 3. In all three cases, the I-V curves are from voltage sweeps $53,54,55$, and 56 in each device. 

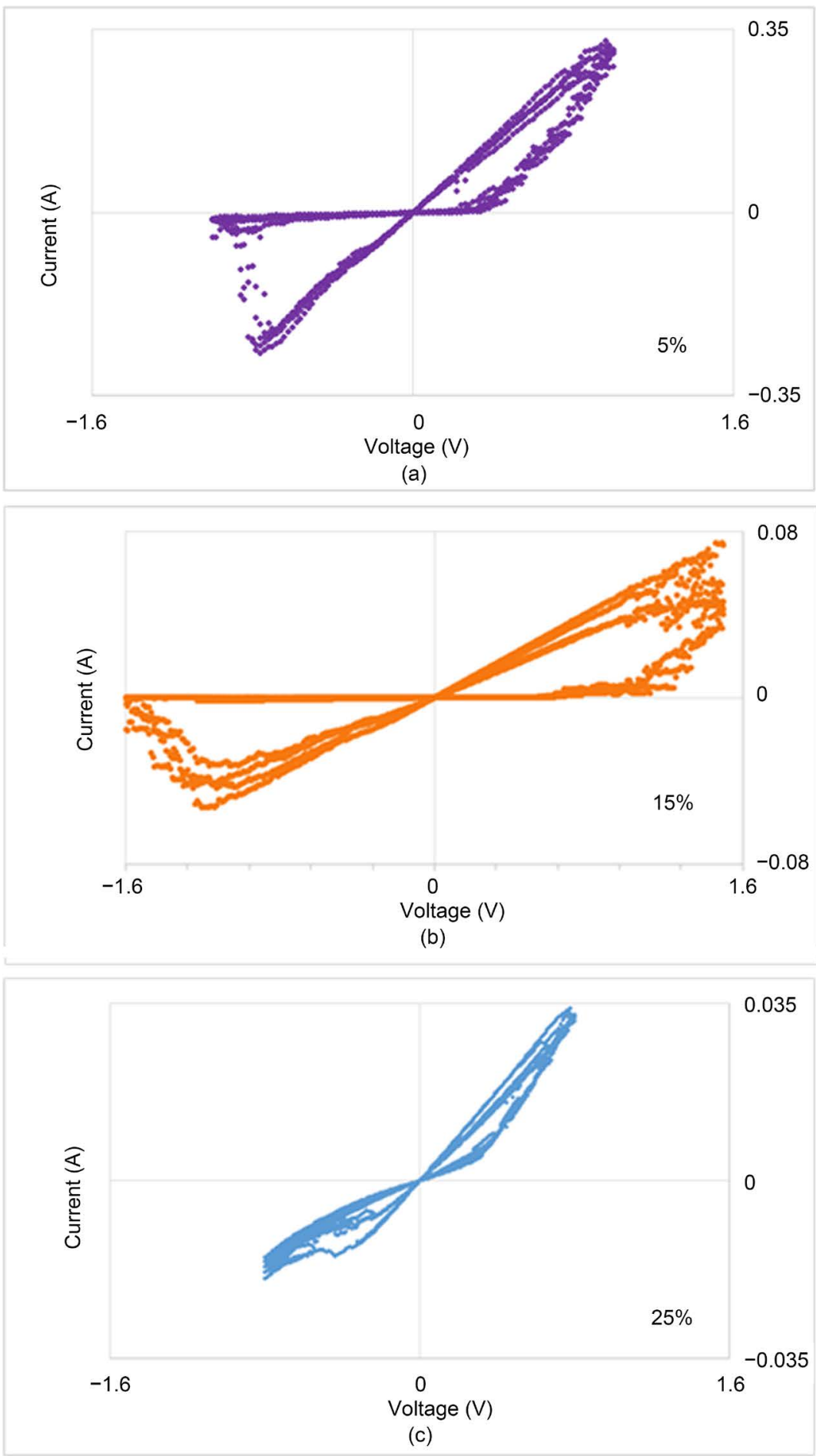

Figure 3. I-V curves for RRAM made with $\mathrm{Ge}_{\mathrm{x}} \mathrm{Sn}_{\mathrm{y}} \mathrm{S}_{\mathrm{z}}$ thin semiconductor films. (a) $5 \%$ Sn content in the film; (b) $15 \%$ Sn content in the film; (c) $25 \%$ Sn content in the film.

The I-V curves made with thin films with low concentrations of Sn have I-V curves where the current increase is somewhat complicated as the sweep voltage increases. Although the conductivity only increases slightly until $0.3 \mathrm{~V}$, at that point it starts to rise more quickly with a moderate slope. At the much higher 
concentration of $\mathrm{Sn}$ of $25 \%$, there is almost no conductivity hold-off and the current increases linearly with a higher slope than for the low Sn percentage case. At intermediate concentrations of Sn, around $15 \% \mathrm{Sn}$, the I-V curves are now more nonlinear, and the conductivity does not change significantly until the voltage sweep rises beyond $1 \mathrm{~V}$. Once it reaches higher than a volt, then the conductivity increases linearly with a high slope and increases by more than 1 order of magnitude in $0.3-0.4$ volts. For the $15 \%$ case as the voltage is increased above some threshold value the conductivity increases sharply, and then decreases as the voltage is lowered to negative values. At a low enough negative value the current again snaps back to the low values encountered at the beginning of the positive sweep. The I-V pattern is somewhat repeatable but changes slightly from one I-V sweep to the next.

\section{Conclusions}

Thin chalcogenide thin films with varying concentrations of Sn were deposited with a PECVD reactor. Based on XRD spectra of the depositions, thin films with Sn concentrations of $8 \%$ and below are largely amorphous as indicated by very broad peaks present in the spectra. At 15\%, the films appear to become more crystalline with some narrow peaks present at $2 \theta$ values consistent with $\mathrm{SnS}_{2}$. At Sn compositions above about $26 \%$, the XRD spectra show a high degree of crystallinity consistent with $\mathrm{SnS}_{2}$, and perhaps $\mathrm{GeS}_{2}$ whose principal peak also occurs at a $2 \theta$ of about 15 degrees.

The Raman spectra show a similar trend with broad spectral structure consistent with both germanium disulfide and tin disulfide at $8 \%$. At $15 \%$ the $\mathrm{SnS}_{2}$ peak becomes more prominent and near $26 \%$ Sn content the spectrum appears as a much narrower peak assignable as $\mathrm{Sn}_{2} \mathrm{~S}_{3}$ or a mixture of $\mathrm{Sn}_{2} \mathrm{~S}_{3}$ and $\mathrm{SnS}_{2}$, and is likely more ordered than the amorphous $\mathrm{GeS}_{2}$ films present at very low $\mathrm{Sn}$ content.

Both the XRD and Raman spectra suggest that the order in the thin film changes significantly from largely amorphous below about $8 \%$ to largely crystalline above about $26 \%$. At $15 \%$ there appears to be a mixture of amorphous and crystalline qualities. This condition appears to be more optimal for the formation of a RRAM memory device as the simple memory devices created with the Sn composition of $15 \%$ have a higher hold-off voltage and more rapid "on-off" switching characteristics. Apparently if the crystallinity is too high there is too much conductance and little hold-off, and when the films are too amorphous the reproduction of the Ag ion channels may be more difficult for each cycle.

\section{Acknowledgements}

We would like to acknowledge Prof. Kris Campbell of BSU for helpful discussions regarding Raman spectra of metal doped germanium chalcogenides.

\section{References}

[1] Edwards, A., Barnaby, H., Campbell, K., Kozicki, M. and Liu, W. (2015) Reconfi- 
gurable Memristive Device Technologies. Proceedings of the IEEE, 103, 1004-1032. https://doi.org/10.1109/JPROC.2015.2441752

[2] Wang, F., Dunn, W., Jain, M., Leo, C. and Vickers, N. (2011) The Effects of Active Layer Thickness on Programmable Metallization Cells Based on Ag-Ge-S. Solid State Electronics, 61, 33-37. https://doi.org/10.1016/j.sse.2011.01.042

[3] Jameson, J., Gilbert, N., Koushan, F., Saenz, J., Wang, J., Hollmer, S., Kozicki, M. and Derhacobian, N. (2012) Quantized Conductance in $\mathrm{Ag} / \mathrm{GeS}_{2} / \mathrm{W}$ ConductiveBridge Memory Cells. IEEE Electron-Device Letters, 33, 257-259. https://doi.org/10.1109/LED.2011.2177803

[4] Campbell, K. and Anderson, C. (2006) Phase Change Memory Devices with Stacked Ge-Chalcogenide/Sn-Chalcogenide Layers. Microelectronics Journal, 38, 52-59. https://doi.org/10.1016/j.mejo.2006.09.012

[5] Vianello, E., Molas, G., Longnos, F., Blaise, P., Souchier, E., Cagli, C., Palma, G., Guy, J., Bernard, M., Reyboz, M., Rodriguez, G., Roule, A., Carabasse, C., Delaye, V., Jousseaume, V., Maitrejean, S., Reimbold, G., DeSalvo, B., Dahmani, F., Verrier, P., Bretegnier, D. and Liebault, J. (2012) Performance and Reliability Booster in Conductive Bridge RAM. Proceedings of the 2012 International Electron Devices Meeting, San Francisco, 741-744. https://doi.org/10.1109/IEDM.2012.6479145

[6] Whitham, P., Strommen, D., Lundell, S., Lau, L. and Rodriguez, R. (2014) $\mathrm{GeS}_{2}$ and $\mathrm{GeSe}_{2}$ PECVD from $\mathrm{GeCl}_{4}$ and Various Chalcogenide Precursors. Plasma Chemistry and Plasma Processing, 34, 755-766. https://doi.org/10.1007/s11090-014-9542-4

[7] Whitham, P., Strommen, D., Lau, L. and Rodriguez, R. (2011) Thin Film Growth of Germanium Selenides from PECVD of $\mathrm{GeCl}_{4}$ and Dimethyl Selenide. Plasma Chemistry and Plasma Processing, 31, 251-256. https://doi.org/10.1007/s11090-010-9278-8

[8] Price, L., Parkin, I., Hardy, A., Clark, R., Hibbert, T. and Molloy, K. (1999) Atmospheric Pressure Chemical Vapor Deposition of Tin Sulfides ( $\mathrm{SnS}, \mathrm{Sn}_{2} \mathrm{Sn}_{3}$, and $\mathrm{SnS}_{2}$ ) on Glass. Chemistry of Materials, 11, 1792-1799. https://doi.org/10.1021/cm990005z

[9] Phillips, B., Steidley, S., Lau, L. and Rodriguez, R. (2001) Coherent Raman Spectroscopic Monitoring of Pulsed Radio Frequency PECVD of Silicon Nitride Thin Films. Journal of Applied Spectroscopy, 55, 946-951. https://doi.org/10.1366/0003702011952785

[10] Shimada, M. and Dachille, F. (1977) Crystallization of Amorphous Germanium Sulfide and Germanium Selenide under Pressure. Inorganic Chemistry, 16, 2094-2097. https://doi.org/10.1021/ic50174a055

[11] Lin, Y., Shi, J., Chen, Y., Chen, C. and Wu, P. (2009) Synthesis and Characterization of Tin Disulfide $\left(\mathrm{SnS}_{2}\right)$ Nanowires. Nanoscale Research Letters, 4, 694-698. https://doi.org/10.1007/s11671-009-9299-5

[12] Sakaguchi, Y., Tenne, D. and Mitkova, M. (2009) Oxygen-Assisted Photoinduced Structural Transformation in Amorphous Ge-S Films. Physica Status Solidi B, 246, 1813-1819. https://doi.org/10.1002/pssb.200982009

[13] Mitkova, M., Chen, P., Ailavajhala, M., Butt, D., Tenne, D., Barnaby, H. and Esqueda, I. (2013) Gamma Ray Induced Structural Effects in Bare and Ag Doped Ge-S Thin Films for Sensor Application. Journal of Non-Crystalline Solids, 377, 195-199. https://doi.org/10.1016/j.jnoncrysol.2012.12.031

[14] Smith, A., Meek, P. and Liang, W. (1977) Raman Scattering Studies of $\mathrm{SnS}_{2}$ and $\mathrm{SnSe}_{2}$. Journal of Physics C: Solid State Physics, 10 1321-1333.

https://doi.org/10.1088/0022-3719/10/8/035 
Submit or recommend next manuscript to SCIRP and we will provide best service for you:

Accepting pre-submission inquiries through Email, Facebook, LinkedIn, Twitter, etc. A wide selection of journals (inclusive of 9 subjects, more than 200 journals)

Providing 24-hour high-quality service

User-friendly online submission system

Fair and swift peer-review system

Efficient typesetting and proofreading procedure

Display of the result of downloads and visits, as well as the number of cited articles Maximum dissemination of your research work

Submit your manuscript at: http://papersubmission.scirp.org/

Or contact msa@scirp.org 